\title{
MADRASAH
}

Jurnal Pendidikan dan Pembelajaran Dasar

p ISSN: 1979-5599 | e ISSN: 2502-194X

P a g e

\section{PENGEMBANGAN KOMIK SAINS UNTUK SISWA SEKOLAH DASAR/MADRASAH IBTIDAIYAH MENUJU BANJARMASIN SIAGA BANJIR}

\author{
Ani Cahyadi', Murniningsih ${ }^{2}$, M. Irfan Islamy ${ }^{3}$ \\ 1;2Universitas Islam Negeri (UIN) Antasari Banjarmasin, ${ }^{3}$ Universitas Islam Negeri (UIN) \\ Maulana Malik Ibrahim Malang \\ 1anicahyadi@uin-antasari.ac.id, 2murniningsih@uin-antasari.ac.id \\ 3irfan.islamy87@pgmi.uin-malang.ac.id
}

\begin{abstract}
Banjarmasin as a lowland city, many small, medium, and large rivers, the majority of swamp areas, would be interesting to be used as an object in education as a place to learn about the knowledge and cultures of the river that characterized by region. The right place is education, especially elementary school which is the most appropriate target in instilling awareness on early. World of education, learning will be interesting if the media are included to make students more excited in the learning process. Comics contained illustration of character, scene, and groove usually arranged as entertainment. in this research developed in the form of science comic based on disaster mitigation, that is flood disaster with hope to be as educative media of learning also as entertainment for student. This research uses model of ADDIE media product development. The research developing two comic entitled "Amang si Pembelajar" and "Belajar Siaga Banjir (BSB)" with good quality in terms of material with a score of 3.22 and excellent quality in terms of learning media with the final average of 3.3. Science comics based on flood mitigation is full color and in accordance with the needs of primary school education and has had ISBN number 602-73178-0-9 and barcode number 9786027317802.
\end{abstract}

Keywords: Comic; Flood; Disaster Mitigation; Elementary School

Copyright (C) 2016 Madrasah Jurnal Pendidikan dan Pembelajaran Dasar. All Right Reserved

\section{A. PENDAHULUAN}

Kota Banjarmasin sebagai ibukota Provinsi Kalimantan Selatan, merupakan daerah dataran rendah di tepian sungai Barito dan Martapura yang rentan akan bencana banjir disamping mayoritas wilayahnya berupa rawa dan berada di bawah permukaan laut pada angka $\pm 70 \mathrm{~mm}$ (Fathurrahman \& Abdurrahman, 2017). Terdapat 11 titik rawan banjir di Kota Banjarmasin yang tersebar pada 5 kecamatan, Kecamatan Banjarmasin Timur, Banjarmasin Tengah, Banjarmasin Barat, Banjarmasin Selatan, dan Banjarmasin Utara (BPPDKalsel, 2012). Hal ini disebabkan karena faktor alam yaitu intensitas hujan dan pasang surutnya sungai Barito \& Martapura, buruknya sistem drainase kota, kurangnya kesadaran lingkungan, pembangunan yang mengikis sungai-sungai dan saluran air, penebangan dan pembalakan liar (Zainuddin, 2013). Apablia hujan datang, seringkali menyebabkan genangan di wilayah Banjarmasin yang hasil penelitiannya terkait saluran drainase eksisting di SWPG Sudi Mampir tidak mampu menampung debit air sehingga sebagian besar banjir (Solikin, Suhartanto, \& Haribowo, 2017).

Banjarmasin yang merupakan kota sungai, terdapat sungai dengan kategori besar,

Vol. 9 No. 1, Desember 2016

Madrasah homepage: http://ejournal.uin-malang.ac.id/index.php/madrasah/index 
sedang, dan kecil, sungai-sungai tersebut membentuk pola aliran dendritic drainage patern (pola aliran daun) sudah seharusnya memperhatikan pembangunan dan insfrastruktur berbasis sungai, khususnya dalam dunia Pendidikan. Pendidikan harus mampu membangun pengetahuan dan kebudayaan berbasis sungai, agar anak-anak generasi selanjutnya bisa dan mampu merawat tempat tinggal mereka sesuai dengan karakteristik geografisnya, bukan sebaliknya membangun perumahan dengan mengurug atau menimbun tanah, dan bahkan membuat rumah dengan memangkas wilayah sungai.

Dibutuhkan langkah pencegahan yang serius salah satunya adalah pemberian edukasi terhadap masyarakat mengenai banjir. Salah satu tempat strategis untuk proses edukasi ini adalah sekolah terlebih jenjang pendidikan dasar. Sebab, semakin dini proses dan edukasi lingkungan ini ditanamkan, semakin optimal kita mempersiapkan generasi mendatang untuk lebih siaga banjir. Oleh karena itu, anak-anak sekolah dasar adalah sasaran yang tepat untuk penanaman kesadaran ini, berikut para gurunya yang memiliki peran melakukan transfer ilmu dan karakter pada anak didiknya.

Media pembelajaran merupakan cara yang tepat dan berperan penting dalam rangka berhasilnya sebuah pembelajaran. Keberhasilan media dalam menyampaikan pesan yang bermakna dan bermanfaat agar dapat diterima semua peserta didik sehingga mampu diimplementasikan dalam kehidupan nyatanya, merupakan hal yang harus di siapkan sebelum memulai sebuah pembelajaran. Maka dibutuhkan media yang sesuai dengan karakter anak dan bisa memberikan edukasi secara efektif seperti komik, yang mengandung warna, gambar dan narasi yang dekat dengan dunia imaginasi anak-anak (Arroio: 2011; Ardiansyah, dkk: 2014; Jalongo 2004). Komik tak hanya mempermudah transfer ilmu pada anak didik, namun juga menumbuhkan minat literasi pada anak yang sejalan dengan program wajib membaca dari pemerintah (Haines, 2012; Mc Cloud, 1994).

Komik mempunyai kemampuan untuk memainkan emosi pembacanya, karena melalui komik karakter yang diinginkan mampu ditampilkan melalui serangkaian gambar dengan penekanan komunikasi yang direkayasa agar dapat menjadi nilai-nilai edukatif (Jalongo, 2004:8), selain itu komik juga mampu seperti prosa yang memberikan informasi dan membangkitkan pertanyaan, sehingga dapat berkontibusi pada pertumbuhan intelektual. Selain itu, untuk merangsang siswa untuk meningkatkan literasi juga perlu digiringi dengan penyediaan bahan bacaan yang mampu memberikan stimulus dan menarik minat mereka, sehingga dengan adanya komik sains berbasis mitigasi bencana banjir selain bertujuan edukatif juga diharapkan sebagai langkah awal dalam membangun budaya literasi yang lebih baik dengan memancing imaginasi dan ketertarikan mereka, sehingga mampu memberikan Pendidikan yang bermakna (meaningful learning). Komik juga mampu meningkatkan hasil belajar serta kemampuan berpikir kritis siswa (Fatimah \& Widyamotko, 2014), meningkatan aspek kognitif serta efektif dalam pembelajaran (Ambaryani \& Airlanda, 2017).

Komik yang dikembangkan berkaitan dengan nilai edukatif dan mitigasi bencana banjir. Isi komik merupakaian serangkaian dasar-dasar dan petunjuk yang memudahkan untuk siswa dalam mempelajari dan mempratikkan tentang mitigasi bencana banjir. Mitigasi merupakan patokan awal dalam rangka mengurangi resiko ketika terjadinya bencana. Dalam mitigasi terdapat tiga tahap yang dilakukan, yaitu sebelum, ketika, dan sesudah terjadinya bencana. Titik tekan mitigasi adalah terminimilasirnya kerugiankerugian yang dapat ditimbulkan akibat bencana.

Banjir adalah bencana yang bisa terjadi akibat alam dan juga akibat perbuatan manusia. Bencana banjir bisa melalui beberapa tahap proses. Tapi juga bisa terjadi secara

Vol. 9 No. 1, Desember 2016

Madrasah homepage: http://ejournal.uin-malang.ac.id/index.php/madrasah/index 


\section{MADRASAH}

Jurnal Pendidikan dan Pembelajaran Dasar

p ISSN: 1979-5599 | e ISSN: 2502-194X

P a g e

mendadak diakibatkan curah hujan yang tinggi yang mengakibatkan debit air naik, sehingga air sungai meluap melebihi batas penampungannya. Banjir dapat membahayakan kehidupan, selain itu banjir juga melumpuhkan aktifitas kehidupan dan rentan penyebaran penyakit.

\section{B. METODE PENELITIAN}

Research and Development (R\&D) menjadi pilihan dalam penelitian ini, dipadukan dengan model pengembangan produk media Analysis, Design, Development, Implementation, dan Evaluate (ADDIE). ADDIE dipilih pada penelitian ini karena merupakan model yang tahapannya sistematis dan instruksional untuk pengembangan produk terlebih media pembelajaran. Tahapan ADDIE pada penelitian pengembang komik ini dirancang sebagai berikut:

1. Analysis. Analisis ini menyesuaikan grand design narasi komik berdasarkan tingkatan usia pada masa anak-anak di Sekolah Dasar dengan kategori mempunyai kemampuan membaca, jadi siswa yang menjadi target adalah dari kelas 3 sd 6 SD/MI. Tujuan pembelajaran disesuaikan dengan Kompentensi Dasar Mitigasi Bencana yang disesuaikan dengan konteks yang berlaku yang berasal dari masalah-masalah yang sering dilakukan oleh masyarakat Banjarmasin dalam kehidupan dan interaksinya dengan sungai, seperti membuang sampah sembarangan di sungai. Pada tahap analisis ini juga disiapkan lembar-lembar instrument yang sudah melewati validasi ahli, diantaranya instrument dari ahli materi, ahli media, ahli desain, dan dari guru SD/MI, hanya instrument dari murid tidak dilaksanakan dikarenakan pada tahap ini uji coba hanya pada guru.

2. Design. Pada tahap ini merupakan blue print atau membuat rancangan. Pada tahap pertama adalah perumusan tujuan, dan pada tahap ini dirancang berdasarkan Rencana Pelaksananaan Pembelajaran (RPP) berdasarkan silabus yang telah tim tetapkan. Selain merumuskan tujuan operasional dan langkah-langkah pembelajaran. Pada tahap ke dua adalah perumusan materi pembelajaran, materi pembelajaran dikembangkan menjadi alur dan narasi komik, selain dalam bentuk komik juga tersedia bahan ajar yang terkait. Alur dan narasi Komik yang dikembangkan ada dua yaitu Amang si Pembelajar (36 halaman) dan Belajar Siaga Banjir "BSB" sebanyak 56 halaman. Karakter dan tokoh mengambil ilustrasi budaya dan tempat di kota Banjarmasin. Penggunaan bahasa ada dua, yaitu bahasa Indonesia (90\%) dan bahasa Banjar (10\%). Pada tahap ke tiga yang dikembangkan adalah perumusan alat pengukur keberhasilan, yaitu evaluasi pembelajaran dalam bentuk tes dan non tes. Pada tahap ini juga dilakukan konsultasi kepada ahli dan telah dilakukan revisi.

3. Development. Pada tahap ini adalah mewujudkan rancangan pada tahap design. Komik yang sudah siap untuk dijadikan media pembelajaran sudah pada kondisi siap dilakukan penyebabaran setelah melalui proses validasi dari ahli.

4. Implementation. Pada tahap ini merupakan penerapan dalam sistem pembelajaran, dalam artian tahap implementasi. Pada tahap ini hanya diterapkan kepada guru-guru kelas SD/MI, dan pada proses selanjutnya akan diterapkan kepada peserta didik.

5. Evaluate. Pada tahap ini, evaluasi yang dilakukan adalah evaluasi dari para guru kelas $\mathrm{SD} / \mathrm{MI}$ sebanyak 25 orang dari sekolah yang berbeda. Hasil dari evaluasi guru kelas ini akan dijadikan pedoman untuk revisi dan pengembangan komik sains berbasis mitigasi

Vol. 9 No. 1, Desember 2016

Madrasah homepage: http://ejournal.uin-malang.ac.id/index.php/madrasah/index 
bencana banjir sebelum benar-benar diterapkan kepada peserta didik.

Secara garis besar, realisasi pemecahan masalah dalam penelitian ini dibagi menjadi tiga tahapan, yaitu tahapan persiapan, tahapan pelaksanaan dan tahapan pasca pelaksanaan. Tahapan persiapan merupakan aktivitas penyusunan dan penyempurnaan proposal. Tahapan pelaksanaan meliputi pengembangan dan validasi instrumen, pengembangan perencanaan pembelajaran dan media komik sains berbasis mitigasi bencana. Evaluasi penelitian ini dilakukan secara partisipatif dengan melibatkan pihak terkait, seperti dinas Pendidikan, pakar materi, pakar media pembelajaran dan guru di Kota Banjarmasin (Hills \& Mullett: 2000). Evaluasi meliputi (1) evaluasi komik sains yang dilakukan oleh pakar materi, pakar media pembelajaran dan guru SD/MI di Banjarmasin. Indikator keberhasilan pada penelitian ini secara umum diukur dari (1) keberadaan komik sains berbasis mitigasi bencana yang sudah tervalidasi dan siap didistribusikan di SD/MI di Banjarmasin; (2) lebih dari $80 \%$ peserta/guru memahami instruksi pembelajaran; (3) lebih dari $75 \%$ guru mampu mempraktekan penjelasan tentang mitigasi bencana banjir; dan (4) lebih dari $75 \%$ guru bersedia melakukan pembelajaran menggunakan komik sains di sekolah masing-masing.

\section{PEMBAHASAN}

Pelaksanaan kegiatan meliputi enam proses: (1) pengembangan dan validasi instrumen, (2) pengembangan ilustrasi komik, (3) penilaian komik dari pakar materi dan pakar media pembelajaran, (4) penilaian Komik dari Guru. Ada empat (4) instrumen yang dikembangkan untuk mengukur keberhasilan program, yaitu: angket penilaian komik dari pakar materi, angket penilaian komik dari pakar media pembelajaran, angket penilaian komik dari guru.

Komik sains yang dikembangkan dalam program ini berlatar masyarakat Banjar beijudul "Amang si Pembelajar" setebal 30 halaman dan "BSB (Belajar Siaga Banjir)" setebal 56 halaman dengan desain full colour dan dicetak di kertas A5. Kedua komik ini menggunakan sekitar $90 \%$ bahasa bahasa Indonesia dansekitar 10\% bahasa Banjar. Berdasarkan pengukuran pakar materi, didapatkan rata-rata skor penilaian 3,22 dengan kategori baik, dengan saran pengembangan berupa penambahan narasi, gambar penjelas narasi seperti gambar biopori, paving stone, dan semisalnya, closing, dan penyajian aspek penanaman karakter kepedulian lingkungan yang lebih halus agar mudah dibaca dan dipahami. Untuk melihat konvenskor dan hasil pengukuran dari ahli materi dapat dilihat pada tabel C.1 dan C.2.

Tabel C.1 Konversi Skor

\begin{tabular}{|ll|}
\hline \multicolumn{1}{|c|}{ Interval Kategori } & \multicolumn{1}{c|}{ Kategori } \\
\hline $1,00-<1,75$ & Tidak Baik \\
\hline $1,75-<2,50$ & Kurang Baik \\
\hline $2,50-<3,25$ & Baik \\
\hline $3,25-4,00$ & Sangat Baik \\
\hline
\end{tabular}

Tabel C.2 Hasil Pengukuran Ahli Materi

\begin{tabular}{|cccc|}
\hline Komponen & $\begin{array}{c}\text { Jumlah } \\
\text { Skor }\end{array}$ & $\begin{array}{c}\text { Rata-Rata } \\
\text { Skor }\end{array}$ & Kategori \\
\hline Materi & 58.00 & 3.22 & Baik \\
\hline
\end{tabular}

Vol. 9 No. 1, Desember 2016

Madrasah homepage: http://ejournal.uin-malang.ac.id/index.php/madrasah/index 


\section{MADRASAH}

Jurnal Pendidikan dan Pembelajaran Dasar

p ISSN: 1979-5599 | e ISSN: 2502-194X

P a g e

Sedang penilaian dari pakar media pembelajaran, didapatkan rata-rata skor penilaian 3,3 dengan kategori sangat baik dengan saran perbaikan seperti penambahan sinopsis pada komik "Amang di Pembelajar", perbaikan tanda baca dan informasi setting, serta penyisipan lebih banyak bahasa Banjar dan budaya keislaman banjar sebagai kearifan lokal. Untuk melihat skor dari ahli media pembelajaran dapat di lihat pada tabel C.3.

Tabel C.3 Hasil Pengukuran Pakar Media Pembelajaran

\begin{tabular}{|c|c|c|c|c|}
\hline Sub Komponen & Rata-rata skor & $\begin{array}{l}\text { Jumlah rata- } \\
\text { rata Skor }\end{array}$ & $\begin{array}{l}\text { Rata-rata } \\
\text { akhir }\end{array}$ & Kategori \\
\hline Anatomi Komik & 3.3 & \multirow{4}{*}{13.3} & \multirow{4}{*}{3.3} & \multirow{4}{*}{ Sangat baik } \\
\hline Kebahasaan & 3.0 & & & \\
\hline Desain dan warna & 3.8 & & & \\
\hline Tampilan Menyeluruh & 3.3 & & & \\
\hline
\end{tabular}

Para guru dilibatkan dalam menilai komik dari aspek materi, anatomi komik, kebahasaan, desain dan warna, dan tampilan menyeluruh berdasarkan instrumen yang dibuat tim. Dari penilaian 13 guru, diketahui bahwa aspek materi memperoleh rata-rata penilaian 3,5 dengan kategori sangat baik; aspek anatomi komik memperoleh rata-rata penilaian 3,5 dengan kategori sangat baik; aspek kebahasaan memperoleh rata-rata penilaian 3,4 dengan kategori sangat baik; pada aspek desain dan warna memperoleh ratarata penilaian 3,4 dengan kategori sangat baik; dan pada tampilan keseluruhan diperoleh rata-rata penilaian 3,5 dengan kategori sangat baik. Maka dapat disimpulkan bahwa guru secara umum menilai sangat baik seluruh aspek penilaian komik.

Tabel C.3 Hasil Penilaian dari Guru Kelas SD/MI

\begin{tabular}{|c|c|c|c|c|}
\hline Penilai & Aspek & $\begin{array}{l}\text { Jumlah rata- } \\
\text { rata Skor }\end{array}$ & $\begin{array}{c}\text { Rata-rata } \\
\text { akhir }\end{array}$ & Kategori \\
\hline \multirow{5}{*}{ Guru } & Instruksi Pembelajaran & 45.4 & 3.5 & \multirow{5}{*}{ Sangat baik } \\
\hline & Materi & 45.0 & 3.5 & \\
\hline & Anatomi Komik & 44.8 & 3.4 & \\
\hline & Kebahasaan & 44.5 & 3.4 & \\
\hline & Desain \& warna & 45.8 & 3.5 & \\
\hline
\end{tabular}

Beberapa masukan dari penilaian oleh guru kelas SD/MI yang dijadikan bahan untuk evaluasi dan revisi adalah terkait mengoperasionalkan Kompetensi Dasar ke dalam tujuan pembelajaran yang lebih spesifik, terkait penggunaan EYD, dan desain yang ditekankan dengan warna yang kuat. Sedang terkait manfaat komik, peserta menilai ilustrasi komik sederhana, menarik, kontennya edukatif dan mudah dipahami peserta didik, mampu menumbuhkan minat baca anak didik, dan menumbuhkan kesadaran anak didik betapa pentingnya menjaga kebersihan. Dengan komik, guru merasa mudah memberikan materi kepada anak-anak tentang mitigasi banjir. Guru juga memberikan masukan dan juga pada umumnya sepakat dengan gagasan pentingnya pembentukan sekolah siaga banjir sebagai sekolah percontohan mengingat SD/MI adalah tempat pendidikan awal yang sangat efektif bagi anak.

Vol. 9 No. 1, Desember 2016

Madrasah homepage: http://ejournal.uin-malang.ac.id/index.php/madrasah/index 


\section{SIMPULAN}

Telah dihasilkan dua komik dengan kualitas baik dari segi materi dan kualitas sangat baik dari segi media pembelajaran. Judul komik yang dikembangkan yaitu "Amang si Pembelajar" dan "BSB (Belajar Siaga Banjir)" dengan full colour dan narasi komik berlatarkan masyarakat Banja, khususnya kota Banjarmasin. Komik ini sesuai dengan kebutuhan pendidikan sekolah dasar juga telah memiliki ISBN dengan nomor 602-731780-9 dengan barcode nomor 9786027317802.

Indikator keberhasilan ini bukan akhir keberhasilan dari kerangka yang lebih luas. Pada kegiatan jangka panjang, berdasarkan rekomendasi, perlu adanya pelatihan bagi guru SD/MI dalam upaya membelajarkan komik sains berbasis mitigasi banjir ini dan pilot project sekolah siaga banjir bagi SD/MI di Kota Banjarmasin maupun sekolah-sekolah di Kalimantan Selatan. Sekolah siaga banjir ini perlu dilengkapi dengan Rencana Aksi Sekolah (RAS) yang berkesinambungan dan akan dilengkapi dengan monitoring dan evaluasi (monev) yang terukur, sehingga program akan lebih efektif.

\section{REFERENSI}

Arcury, Thomas. (2000). Successful Models of Community-Based Participatory Research. Final Report. Liam R. O'Fallon, Frederick L. Tyson, Allen Dearry (Eds.) National Institute of Environmental Health Sciences.

Ardiansyah, dkk. (2014). Perancangan Buku Komik Matematika Khusus Siswa Kelas IV dengan Konsep Magic of Maths. Jurnal Sains dan Seni Pomits. 3 (1): 24-27.

Arroio, Agnaldo. (2011). Comics as a Narrative in Natural Science Education. Western Anatolia Journal of Educational Sciences (WAJES), pg. 93-98. Izmir, Turkey: Dokuz Eylul University Institute

Ambaryani, A., \& Airlanda, G. S. (n.d.). Pengembangan Media Komik Untuk Efektifitas Dan Meningkatkan Hasil Belajar Kognitif Materi Perubahan Lingkungan Fisik. Jurnal Pendidikan Surya Edukasi, 3(1), 19-28.

Fathurrahman, F., \& Abdurrahman, A. (2017). Penyuluhan Tentang Pembangunan Rumah sistem Panggung Untuk Mengurangi dampak Air Pasang/Banjir di Kota Banjarmasin. Al-ikhlas jurnal pengabdian, 3(1).

Solikin, S., Suhartanto, E., \& Haribowo, R. (2017). Analisis Penanganan Genangan Pada Wilayah Kota Banjarmasin. Jurnal Teknik Pengairan, 8(1), 15-25.

Zainuddin, Hasan. (2013). Banjarmasin Banjir Akibat Sampah. (Online), (http:/ / www.antarakalsel.com/berita/ 14979/banjir-banjarmasin-akibat- sampah, diakses tanggal 15 April 2015)

Zubaidah, Neneng. (2015). Lima Provinsi Pilot Project Gerakan Membaca (Online), (http://nasional.sindonews.com/read/1035271/144/lima-provinsi-pilot- projectgerakan-membaca-1440082995, diakses tanggal 11 Januari 2016)

Vol. 9 No. 1, Desember 2016

Madrasah homepage: http://ejournal.uin-malang.ac.id/index.php/madrasah/index 


\section{MADRASAH}

Jurnal Pendidikan dan Pembelajaran Dasar

p ISSN: 1979-5599 | e ISSN: 2502-194X

Lampiran 1

Contoh Komik Belajar Siaga Banjir (BSB)

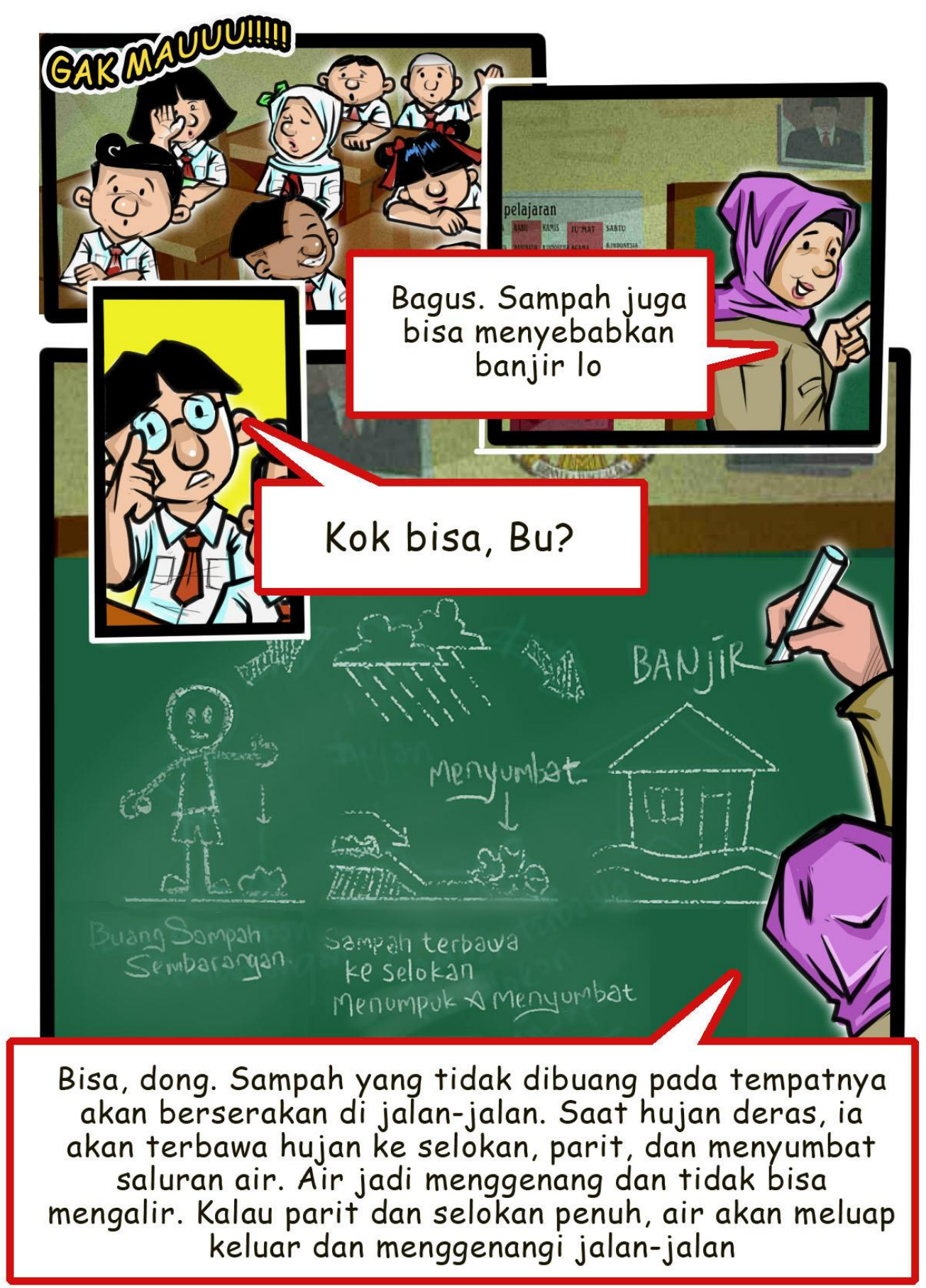

Vol. 9 No. 1, Desember 2016

Madrasah homepage: http://ejournal.uin-malang.ac.id/index.php/madrasah/index 
Lampiran 2

Contoh Komik Amang si Pembelajar

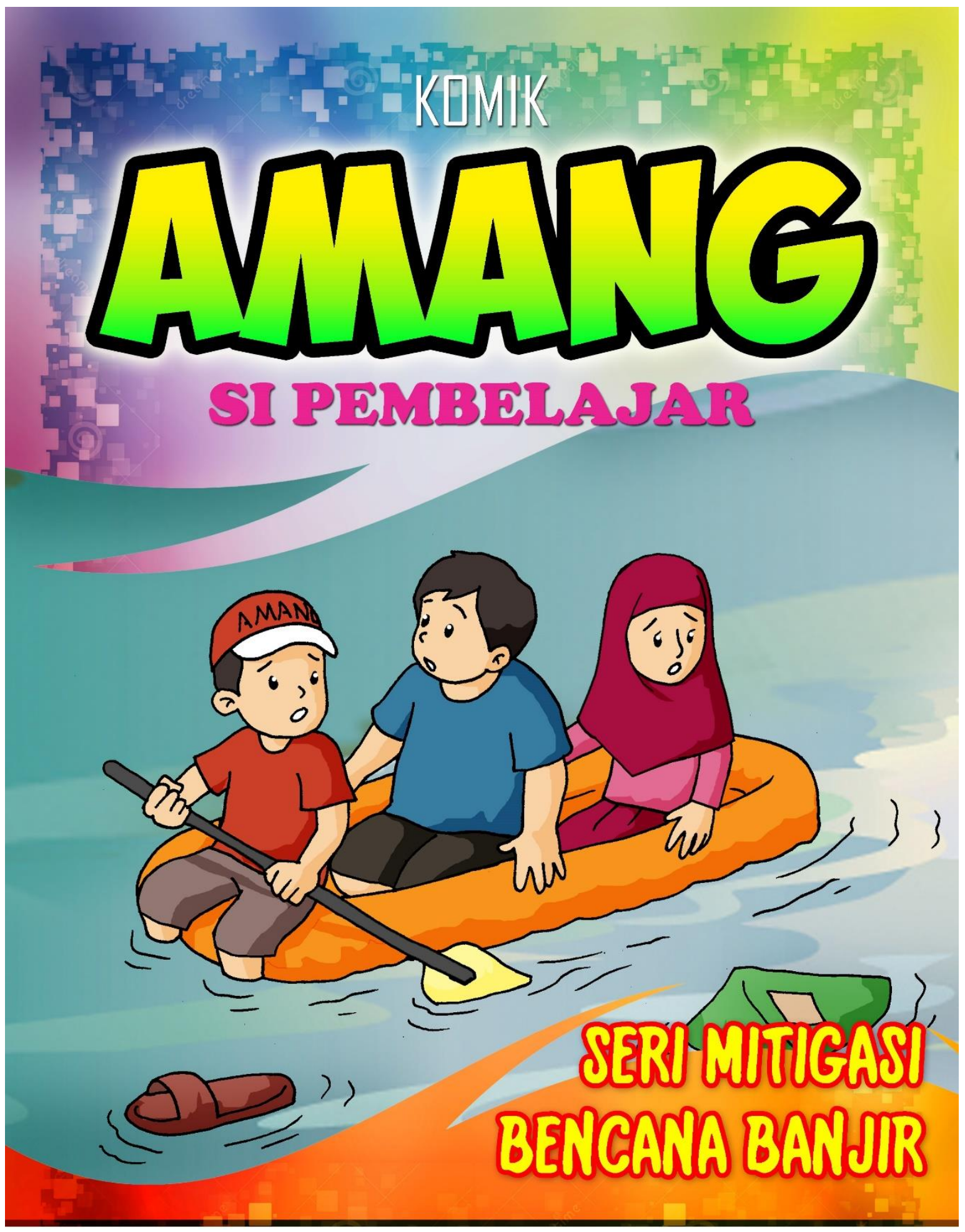

Vol. 9 No. 1, Desember 2016

Madrasah homepage: http://ejournal.uin-malang.ac.id/index.php/madrasah/index 